\title{
Encefalomeningocelo: Por Dentro da Imagem
}

\author{
Encephalomeningocele: Inside the Picture
}

Alexandra P. PINTO $\rrbracket^{1}$, Cláudia GOMES ${ }^{1}$, Cláudia C. FARIA², José MIGUÉNS ${ }^{2}$, Joana SALDANHA ${ }^{1}$ Acta Med Port 2016 Feb;29(2):143-143 - http://dx.doi.org/10.20344/amp.6625

Palavras-chave: Encefalocele; Meningocele; Recém-Nascido.

Keywords: Encephalocele; Infant, Newborn; Meningocele.

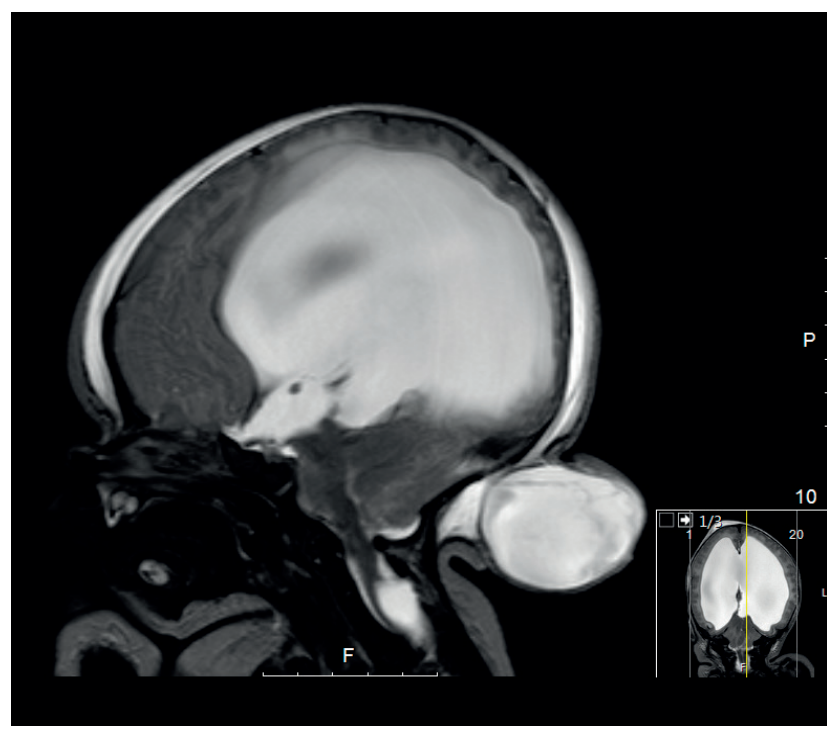

Figura 1 - Ressonância magnética e neuro-eixo: encefalomeningocelo

Recém-nascido do sexo masculino, gravidez de termo vigiada com ecografias obstétricas descritas como normais e serologias negativas. Antecedentes pessoais maternos de obesidade. Parto por cesariana, com peso ao nascer 4650 gr (grande para idade gestacional). Macrocrânea (PC $41 \mathrm{~cm} \mathrm{P} \mathrm{>} \mathrm{95),} \mathrm{fontanela} \mathrm{anterior} \mathrm{tensa} 5 \times 5 \mathrm{~cm} \mathrm{e}$ tumefação violácea na região mediana occipital, epitelizada, de consistência duroelástica, com cerca de $7 \times 4 \mathrm{~cm}$ de diâmetro. Ressonância magnética de crânio e neuro-eixo revelou "defeito ósseo na escama occipital mediana... procidência nas partes moles suboccipitais de formação quística arredondada com $47 \mathrm{~mm}$ contendo líquido cefalorraquidiano, meninge e tecido parenquimatoso residual encefalomeningocelo e hidrocefalia activa." Face à presença de hidrocefalia máxima, foi colocado inicialmente (D4) um sistema de derivação ventrículo-peritoneal (SDVP).

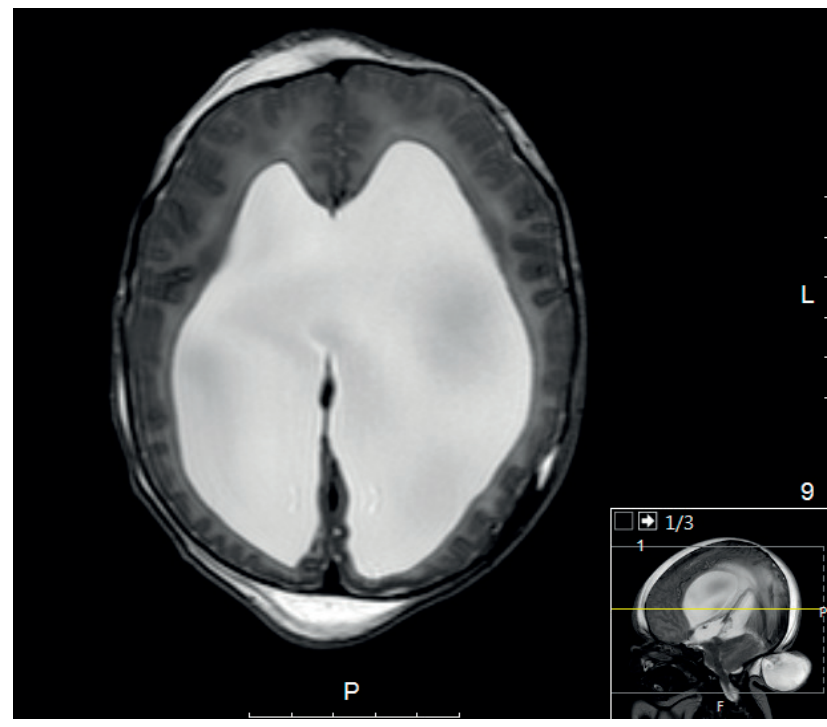

Figura 2 - Ressonância magnética de crânio e neuro-eixo: hidrocefalia

A correção do encefalomeningocelo foi diferida para um segundo tempo cirúrgico (D20) no qual por macrocrânia e persistência da ventriculomegália efetuou-se uma ventricuIostomia endoscópica do pavimento do III ventrículo.

O encefalomeningocelo occipital é uma malformação congénita rara do sistema nervoso caracterizada pela ausência de encerramento do tubo neural durante o desenvolvimento fetal. As morbilidades e alterações no desenvolvimento cognitivo destes doentes dependem da localização e do tipo de tecido cerebral envolvido, existência de hidrocefalia bem como da presença de anomalias congénitas associadas. Uma abordagem por equipa multidisciplinar é fundamental no seguimento destes doentes. Atualmente com 8 meses de idade, este latente apresenta estabilização da macrocrânea mas marcado atraso do desenvolvimento psicomotor.

\section{REFERÊNCIAS}

1. Ugras M, Karabekir HS, Karak O, Sen TA, Alpay F. Occipital encephalocele: report of case series. Arch Dis Child. 2012;97:167-8.

2. Kiymaz N, Yilmaz N, Demir I, Keskin S. Prognostic factors in patients with occipital encephalocele. S. Pediatrics Neurosurg. 2010;46:6-11.

\footnotetext{
1. Serviço de Neonatologia. Departamento de Pediatria. Centro Hospitalar Lisboa Norte. Lisboa. Portugal.

2. Serviço de Neurocirurgia. Centro Hospitalar Lisboa Norte. Lisboa. Portugal.

$\bowtie$ Autor correspondente: Alexandra P. Pinto. alexandra.r.pinto@gmail.com

Recebido: 20 de maio de 2015 - Aceite: 04 de setembro de 2015 | Copyright @ Ordem dos Médicos 2016
} 